\title{
Sağlık Çalışanlarının İyonize Radyasyon ve Radyoaktif Maddelerden Korunmaya Yönelik Bilgilerinin Belirlenmesi
}

\author{
Determination of Health Employees Knowledge of Ionized Radiation and Radioactive Ingredients
} Ayşegül DÖNMEZ ${ }^{1}$, Aytuğ TÜRK ${ }^{2}$, Askeri BACAK ${ }^{3}$, Özgür DEMİR ŞENTÜRK ${ }^{4}$

\section{ÖZ}

$\mathrm{Bu}$ araştırmada sağlık çalışanlarının iyonize radyasyon ve radyoaktif maddelerden korunmaya yönelik bilgilerinin belirlenmesi amaçlanmıştır.

Tanımlayıcı tipteki bu araştırmanın örnek grubunu bir üniversite hastanesindeki radyoloji ve radyasyon onkolojisi klinik çalışanları oluşturmaktadır ( $\mathrm{N}=97)$. Araştırmada veri toplama aracı olarak tanıtıcı bilgi formu ve radyasyondan korunmaya yönelik bilgi formu kullanılmıştır. Tanıtıcı bilgi formu; yaş, meslek gibi dokuz tanıtıcı sorudan oluşmaktadır. Radyasyondan Korunmaya Yönelik Bilgi Formu; araştırmacılar tarafından literatür taranarak oluşturulan akrostiş yapısında hazırlanan radyasyondan korunmayı içeren 19 maddeli bilgi formudur. Çalışmamız için üniversite etik kurulu onayı alınmıştır. Araştırma verilerinin analizleri SPSS 15.0 programı ile yapılmıştır.

Katılımcıların \%36,1'inin eldiven, gözlük, kurşun önlük gibi koruyucu donanımı kullanmadığ1 tespit edilmiş, \%45,4'ü dozimetreyi önlük içine taktığında tüm vücudun aldığı radyasyon miktarı hakkında bilgi verdiğini düşündüğü, $\% 60,8$ 'i radyolojik tetkikler sırasında hastaya dokunmaması gerektiğini, \%46,4’ü gebe çalışanların batın bölgelerini kurşun önlükle korusalar dahi denetimli alanlarda çalışamayacağını ve \%63,9'u denetimli alanlarda 18 yaş altı stajyerlerin çalıştırılamayacağını bilmediği belirlenmiştir.

Araştırma sonucuna göre, sağlık çalışanlarının radyasyondan korunmaya yönelik bilgiye ihtiyaçları olduğu ve eğitim almaları gerektiği söylenebilir.

Anahtar Kelimeler: Radyasyon, Sağlık Çalışanları, Korunma, Radyoaktif Madde

\section{ABSTRACT}

In this study, it was aimed to determine the knowledge of healthcare professionals for protection from ionizing radiation and radioactive materials.

The sample group of this descriptive study consists of radiology and radiation oncology clinicians in a university hospital $(\mathrm{N}=97)$. In the research, introductory information form and radiation protection information form were used as data collection tools. Introductory information form; It consists of nine introductory questions such as age and occupation. Information Form for Radiation Protection; This is a 19-item information form that includes radiation protection prepared in the acrostic structure created by the researchers by searching the literature. University ethics committee approval was obtained for our study. The analysis of the research data was done with the SPSS 15.0 program.

It was determined that $36.1 \%$ of the participants did not use protective equipment such as gloves, glasses, lead apron, $45.4 \%$ of them thought that they gave information about the amount of radiation received by the whole body when they put the dosimeter into the apron, $60.8 \%$ of them were given to the patient during radiological examinations. It was determined that $46.4 \%$ of pregnant workers could not work in controlled areas even if they protected their abdominal areas with lead aprons and $63.9 \%$ of them could not be employed in supervised areas.

According to the results of the research, it can be said that healthcare professionals need information and need training for radiation protection.

Keywords: Radiation, Health Workers, Protection, Radioactive Material

Çalışma için Etik Kurul'dan (EGEBAYEK 06/19-247-2017) izin alınmıştır.

${ }^{1}$ Prof. Dr. Ayşegül DÖNMEZ, Ruh Sağlığı ve Hastalıkları Hemşireliği, Ege Üniversitesi Hemşirelik Fakültesi, aysegul.donmez@ege.edu.tr, ORCID: 0000-0002-1087-9173

${ }^{2}$ Arş. Gör. Aytuğ TÜRK, Ruh Sağlığı ve Hastalıkları Hemşireliği, Ege Üniversitesi Hemşirelik Fakültesi, aytug.turk@hotmail.com, ORCID:0000-0003-4066-3004

${ }^{3}$ Hemşire, Askeri BACAK, Bursa Şehir Hastanesi, askeri-bacak_@ outlook.com, ORCID: 0000-0003-2645-2120

${ }^{4}$ Yüksek Lisans Öğrencisi, Özgür DEMIR ȘENTÜRK, Ege Üniversitesi Sağlık Bilimleri Enstitüsü, ozgurdmrsntrk@hotmail.com, ORCID: 0000-0002-1444-7837

İletişim / Corresponding Author: e-posta/e-mail:
Geliș Tarihi / Received: 30.12 .2020

Kabul Tarihi/Accepted: 30.06 .2021 
On dokuzuncu yüzyılın sonlarında $\mathrm{X}$ 1şınları ve radyoaktivitenin keşfedilmesinden günümüze kadar geçen süreç boyunca iyonize radyasyonun çeşitli tıbbi tanısal yöntemlerde, cerrahi yöntemlere ek olarak kanser tedavisinde, kesin tarihleme yöntemi olarak arkeoloji ve jeolojide, besinlerin bozulma ve çürümesini engellemek için gida endüstrisinde olmak üzere farklı uygulamalarda kullanımı mevcuttur. Radyasyonun günlük hayatımıza bu denli nüfuz etmiş olması toplumsal yaşamı kolaylaştırmasının yanı sıra bağlı birçok sağlık sorununu da beraberinde getirmektedir. $\mathrm{Bu}$ nedenle radyasyonun insan yaşamı üzerindeki olumsuz etkileri ve bu etkilerden korunma yöntemleri her geçen gün giderek önem kazanmaktadır. ${ }^{1-5}$

Olumsuz etkiler maruz kalınan doz, yaş, süre, cins ve metabolik duruma göre değişiklik göstermekle birlikte bir kısmı genetik, bir k1sm1 ise somatik etkiler oluşturmaktadır. ${ }^{6}$ Genetik etkiler radyasyon ile etkilenen kişilerde değil daha sonraki

\section{GİRIŞ}

nesillerde ortaya çıkarken; somatik etkiler ise radyasyon ile etkilenen kişilerin bizzat kendisinde ortaya çıkmaktadır. ${ }^{7}$ Yaptıkları iş gereği iyonize radyasyona düşük doz dahi olsa yıllar boyunca en fazla maruz kalan meslek grubu olan radyoloji çalışanlarında bu etkiler gerek kısa dönem içerisinde, gerekse uzun yillar sonrasinda bile ortaya çıkabilmektedir. ${ }^{8}$ Kısa dönem etkiler genel olarak alınan radyasyonun dozuna bağlı olarak değișkenlik gösterdiği belirtilirken, uzun dönem etkilerin ise 1şınlamaların tekrarı ve bu tekrarlamalara bağlı oluşan hasarın organizma tarafindan yeterince onarılamaması ile ilișkilendirildiği görülmektedir. ${ }^{9-11} \mathrm{Bu}$ durum radyoloji de çalışan sağlık personeli açısından büyük bir risk yaratmaktadır. ${ }^{12-14}$

$\mathrm{Bu}$ noktadan hareketle bu araştırma, çalışma koşulları bakımından riskli grupta yer alan radyoloji çalışanlarının ortam, çalışan ve hasta sağlığına yönelik bilgi tutum ve davranışlarını değerlendirmek amacıyla tasarlanmıştır.

\section{MATERYAL VE METOT}

\section{Araştırmanın Tipi}

Tanımlayıcı tipte olan bu çalışma Ege bölgesinde bir üniversite hastanesinde gerçekleştirilmişstir.

\section{Araştırmanın Evren ve Örneklemi}

Araştırma bir üniversite hastanesindeki radyoloji $(\mathrm{N}=57)$ ve radyasyon onkolojisi kliniğinde çalışan $(\mathrm{N}=40)$ ve araştırmaya katılmayı kabul eden toplam 97 sağlık çalışanı ile gerçekleştirilmiştir.

\section{Veri Toplama Araçları}

Araştırmada veri toplama aracı olarak, tanitıc1 bilgi formu ve radyasyondan korunmaya yönelik bilgi formu kullanılmıştır. Tanıtıcı Bilgi Formu, yaş, meslek gibi soruların yer aldığı toplam dokuz adet sorudan oluşmaktadır. Radyasyondan Korunmaya Yönelik Bilgi Formu ise, araştırmacıların literatür taraması sonrasında oluşturmuş oldukları, akrostiş yapıda hazırlanan ve radyasyondan korunmaya yönelik bilgileri içeren 19 maddelik formdan oluşmaktadır. ${ }^{7-11}$

Baş harfleri "RADYASYONDAN KORUNMA" olan soru formuna verilen alternatif cevaplar "doğru, yanlış, bilmiyorum', şeklinde sıralanmıştır.

\section{Verilerin Toplanması}

Veri toplama formları araştırmacılar tarafindan Ocak 2018-Mayıs 2018 tarihleri arasında yüz yüze görüşme yöntemiyle uygulanmıştır. Formlar teslim alınırken örneklem grubuna $(\mathrm{N}=97)$ bilgi formunun cevap anahtarı ve radyasyondan korunmada etkili bir bitki olan kaktüs tohumları zarf içinde hediye edilmiştir.

\section{Verilerin Değerlendirilmesi}

Çalışmadan elde edilen veriler Statiscial Package for Social Sciences (SPSS) 15.0 programı ile analiz edilmiş olup, sayısal 
değişkenler ortalama, kategorik değişkenler sayı ve yüzde olarak ifade edilmiştir.

\section{Araştırmanın Etik Yönü}

Araştırma için Ege Üniversitesi Tıp Fakültesi Başhekimliğinden kurum izni, (Tarih:26/12/2017, Say1 No:69631334-100), Ege Üniversitesi Bilimsel Araştırma ve Yayın Etiği Kurulları etik kurul izni (Karar Tarih/No: 06/19-247-2017) ve katılımcıların aydınlatılmıș onamları alınmıştır.

\section{Araştırmanın Kısıtlılıkları}

Araştırmanın yalnızca bir üniversite hastanesindeki, radyoloji ve radyasyon onkolojisi kliniğinde çalışan sağlık çalışanları ile yürütülmüş olması araştırmanın kısıtlılığını oluşturmaktadır.

\section{BULGULAR VE TARTISSMA}

Tablo 1. Katılımcıların Tanımlayıcı Özelliklerine Göre Dağılımı

\begin{tabular}{|c|c|c|}
\hline Değişkenler & Sayı & Yüzde \\
\hline \multicolumn{3}{|l|}{ Yaş Aralığı } \\
\hline $25-34$ & 20 & 20,6 \\
\hline $35-44$ & 41 & 42,3 \\
\hline $45-54$ & 33 & 34 \\
\hline $55-59$ & 3 & 3,1 \\
\hline \multicolumn{3}{|l|}{ Cinsiyet Durumu } \\
\hline Kadin & 52 & 53,6 \\
\hline Erkek & 45 & 46,4 \\
\hline \multicolumn{3}{|l|}{ Medeni Durumu } \\
\hline Evli & 78 & 80,4 \\
\hline Bekar & 19 & 19,6 \\
\hline \multicolumn{3}{|l|}{ Eğitim Durumu } \\
\hline Lise & 6 & 6,2 \\
\hline Ön Lisans & 33 & 34 \\
\hline Lisans & 38 & 39,2 \\
\hline Lisans Üstü & 20 & 20,6 \\
\hline \multicolumn{3}{|c|}{ Kurumda Çalışma } \\
\hline \multicolumn{3}{|c|}{ Süresi (Yıl) } \\
\hline $0-9$ & 23 & 23,7 \\
\hline $10-19$ & 38 & 39,2 \\
\hline $20-29$ & 28 & 28,9 \\
\hline 30 ve üzeri & 8 & 8,2 \\
\hline \multicolumn{3}{|l|}{ Mesleki Durumu } \\
\hline Doktor & 23 & 23,7 \\
\hline Tekniker & 57 & 58,8 \\
\hline Hemşire & 15 & 15,5 \\
\hline Medikal Fizikçi & 2 & 2,1 \\
\hline Toplam & 97 & 100 \\
\hline
\end{tabular}

Tablo 1'de sağlık çalışanlarının bazı tanımlayıcı özelliklerine göre dağılımları yer almaktadır. Katılımcıların \%42,3'ü 45-49 yaş arasında, \%53,6'sı kadın, \%80,4'ü evli, \%39,2'si lisans mezunu, \%39,2'si 10-19 yil aralığında şu anki çalıştığı kurumda görev yapmakta olup, $\% 58,8^{\prime} i$ ise tekniker olarak $\% 23,7$ 'si ise doktor olarak görev yapmaktadır.
Tablo 2. Sağlık Çalışanlarının Radyasyon Eğitimi Durumlarının İncelenmesi

\begin{tabular}{lrr}
\hline \multicolumn{1}{l}{ Değişkenler } & \multicolumn{2}{c}{ Yüzde } \\
& & \\
\hline $\begin{array}{l}\text { Radyasyondan } \\
\text { korunma ile ilgili } \\
\text { eğitim alma durumu }\end{array}$ & & \\
Evet & 86 & 88,7 \\
Hayır & 11 & 11,3 \\
\hline Alınan Eğitim Türü & & \\
İnternet & 2 & 2,1 \\
Mesleki Eğitim & 75 & 77,3 \\
Kurs & 15 & 15,5 \\
Diğer & 5 & 5,2 \\
\hline Korunma Yöntemi & & \\
Donanım (gözlük, & 62 & 63,9 \\
eldiven, maske vb.) & & \\
Mesafe & 33 & 34,0 \\
Cihaz Kalibrasyonu & 11 & 11,3 \\
\hline Toplam & 97 & 100 \\
\hline
\end{tabular}

Tablo 2'de sağlık çalışanlarının radyasyondan korunma ile ilgili eğitim alma durumlarına yönelik veriler yer almaktadır. Buna göre katılımcıların \%88,7'si radyasyondan korunma eğitimi aldığını, eğitim alanların \%77,3'ünün eğitimi mesleki olarak aldığını, \%63,9'u radyasyondan korunmak için donanım (gözlük, eldiven, maske vb.) kullandığını belirtmiştir.

Tablo 3. Sağlık Çalışanlarının Radyasyondan Korunmaya Yönelik Bilgi Formuna Verdikleri Cevapların Cevap Anahtarına Göre Dağılımı

\begin{tabular}{ll}
\hline Değişkenler & $\begin{array}{l}\text { Cevap } \\
\text { Anahtarı / } \\
\text { Cevapların } \\
\text { Dağılım } \\
\text { Yüzdesi }\end{array}$ \\
\hline $\begin{array}{l}\text { Radyoaktif ilaç hazırlarken eldiven, } \\
\text { gözlük, önlük gibi koruyucu malzeme }\end{array}$ & \multicolumn{1}{c}{$\%$} \\
kullanılmalıdır. & \\
\hline
\end{tabular}




\begin{tabular}{|c|c|}
\hline $\begin{array}{l}\text { GÜSBD 2021; 10(1): } \mathbf{8 7 6}-\mathbf{8 8 2} \\
\text { GUJHS 2021; 10(1): } 876-882\end{array}$ & $\begin{array}{l}\text { Gümüşhane Ünivers } \\
\text { Gümüşhane Universi }\end{array}$ \\
\hline \multicolumn{2}{|l|}{ Tablo 3 (Devamı) } \\
\hline $\begin{array}{l}\text { Aktivite, radyoaktif maddenin belirli bir } \\
\text { zaman aralığındaki bozunma miktarını } \\
\text { ifade etmektedir. }\end{array}$ & $\begin{array}{r}\mathrm{D} \\
\% 88,7\end{array}$ \\
\hline Değişkenler & $\%$ \\
\hline $\begin{array}{l}\text { Doğal radyasyon ve radyoaktif maddeler } \\
\text { hakkında bilgi sahibiyim. }\end{array}$ & $\begin{array}{r}\mathrm{D} \\
\% 90,7 \\
\end{array}$ \\
\hline $\begin{array}{l}\text { Yapay radyasyon kaynakları, X 1şınları ve } \\
\text { nükleer serpintilerdir. }\end{array}$ & $\begin{array}{r}\mathrm{D} \\
\% \\
90,7 \\
\end{array}$ \\
\hline $\begin{array}{l}\text { Az miktarda radyasyona maruz kalmak } \\
\text { sağlık açısından önemlidir. }\end{array}$ & $\begin{array}{r}\mathrm{D} \\
\% 85,6 \\
\end{array}$ \\
\hline $\begin{array}{l}\text { Santral sinir sistemine etkileri; IQ } \\
\text { azalmasına ve mikrosefaliye neden olur. }\end{array}$ & $\begin{array}{r}\mathrm{D} \\
\% 59,8 \\
\end{array}$ \\
\hline $\begin{array}{l}\text { Yapay radyasyon kaynakları; tıbbi, zirai } \\
\text { ve endüstriyel alanlarıdır. }\end{array}$ & $\begin{array}{r}\mathrm{D} \\
\% 76,3\end{array}$ \\
\hline $\begin{array}{l}\text { Olası bir radyasyon maruziyetinde } \\
\text { monitöring testi yapılır. }\end{array}$ & $\begin{array}{r}\mathrm{D} \\
\% 74,2 \\
\end{array}$ \\
\hline $\begin{array}{l}\text { Nükleer tıp hastalıklara tanı konulması ya } \\
\text { da sağaltım amacıyla 1şın etkin } \\
\text { (radyoaktif) izotopların kullanılmasını } \\
\text { gerektiren hekimlik dalıdır. }\end{array}$ & $\begin{array}{r}\mathrm{D} \\
\% 88,7\end{array}$ \\
\hline $\begin{array}{l}\text { Denetimli alanlarda } 16-18 \text { yaş } \\
\text { aralığındaki stajyer öğrenciler alınan } \\
\text { eğitim izni dâhilinde çalıştırılabilir. }\end{array}$ & $\begin{array}{r}\mathrm{Y} \\
\% 36,1\end{array}$ \\
\hline $\begin{array}{l}\text { Az miktarda radyoaktif madde dökülmesi } \\
\text { halinde temizleninceye kadar emici bez } \\
\text { ya da kağıda emdirerek yayılmasını } \\
\text { engellenir. }\end{array}$ & $\begin{array}{r}\mathrm{D} \\
\% 57,7\end{array}$ \\
\hline $\begin{array}{l}\text { Nicelik bakımından daha fazla radyoaktif } \\
\text { madde dökülmesi durumunda bulaş } \\
\text { olmuş giysi ve ayakkabı içeride bırakılıp } \\
\text { kapı kapatılıp yetkili çağırmak için ortam } \\
\text { terk edilir. }\end{array}$ & $\begin{array}{r}\mathrm{D} \\
\% 81,4\end{array}$ \\
\hline Kurşun veya beton bariyerler radyasyon & $\mathrm{D}$ \\
\hline korunmasında paravan oluşturur. & $\% 81,4$ \\
\hline $\begin{array}{l}\text { Ortam denetimli alan kapsamında ise } \\
\text { hamileliği belirlenmiş çalışanlar batın ve } \\
\text { uterus bölgelerini koruyucu önlük ile } \\
\text { koruyarak çalışabilirler. }\end{array}$ & $\begin{array}{r}\mathrm{Y} \\
\% 53,6\end{array}$ \\
\hline $\begin{array}{l}\text { Radyoloji çalışanlarının kullandığ } 1 \\
\text { dozimetre koruyucu önlük içine takıldığ } 1 \\
\text { zaman tüm vücudun aldığı radyasyon } \\
\text { miktarı hakkında bilgi verir. }\end{array}$ & $\begin{array}{r}\mathrm{Y} \\
\% 50,5\end{array}$ \\
\hline $\begin{array}{l}\text { Uzaklık radyolojik tetkiklerde önemli bir } \\
\text { parametre olup hastadan yaklaşık } 3 \mathrm{~m} \\
\text { uzaklıkta saçılma düzeyi hızla düşer ve } \\
\text { kurşun önlük giymek gerekmeyebilir. }\end{array}$ & $\begin{array}{r}\mathrm{D} \\
\% 72,2\end{array}$ \\
\hline $\begin{array}{l}\text { Nefes ile solunum sistemine ya da } \\
\text { sindirim sistemine radyoaktif madde } \\
\text { geçebilecek alanlarda, emzirme } \\
\text { döneminde bulunan kadınlar } \\
\text { çalıştırılamaz. }\end{array}$ & $\begin{array}{r}\mathrm{D} \\
\% 76,3\end{array}$ \\
\hline $\begin{array}{l}\text { Mümkün olduğunca radyolojik tetkik ve } \\
\text { tedaviler esnasında terapötik dokunmaya } \\
\text { yer verilerek hastanın anksiyetesi } \\
\text { azaltılmalıdır. }\end{array}$ & $\begin{array}{r}\mathrm{D} \\
\% 60,8\end{array}$ \\
\hline $\begin{array}{l}\text { Afetler, yangın, patlama vb. acil } \\
\text { durumlarda radyoaktif maddeler özel } \\
\text { kaplarda taşınır ve ortamda doğal düzeyin } \\
\text { üzerinde radyasyon bulunması halinde } \\
\text { bile kurtarma ve ilkyardım işlemleri } \\
\text { hiçbir şekilde engellenmez. }\end{array}$ & $\begin{array}{r}\mathrm{D} \\
\% 69,1\end{array}$ \\
\hline
\end{tabular}

Tablo 3 'de sağlık çalışanlarının radyasyondan korunmaya yönelik bilgi formuna verdikleri cevapların, cevap anahtarına göre dağılımı yer almaktadır. Katılımcıların toplamda en fazla doğru cevabı verdiği ifade \%97,9 ile "Radyoaktif ilaç hazırlarken eldiven, gözlük, önlük gibi koruyucu malzeme kullanılmalıdır." olurken yanlış cevabın en çok verildiği soru ise \%36,1 ile "Denetimli alanlarda 16-18 yaş aralığındaki stajyer öğrenciler alınan eğitim izni dâhilinde çalıştırılabilir." ifadesine verdikleri görülmüştür.

Radyolojik incelemelere tabi tutulan kişiler ve radyoloji çalışanlarında radyasyona bağlı istenmeyen durumları en aza indirgemek için çeşitli uluslararası kuruluşlar tarafından alınan kararlar doğrultusunda yönetmelikler çıkarılarak, yıllık maksimum müsaade edilecek doz limitleri belirlenmiştir. Araştırmamızdaki katılımcıların \%85,6's1 az miktarda radyasyona maruz kalmanın sağlık açısından önemli olduğunu düşünmektedir. İşlemler sırasında radyasyondan korunmak için eldiven, gözlük, tiroid koruyucu ve önlük gibi koruyucu donanımın kullanılması gerektiğine doğru şeklinde cevap verenler tüm grubun \%97,9'u olmasina rağmen (Tablo 3), bu donanımları kullandığını belirtenlerin sayısinin grubun \%63,9'u olduğu görülmektedir (Tablo 2). Doğru uygulamayı bildiği halde uygulamayanların sayısının oldukça fazla olması dikkat çeken bir bulgudur. Khamtuikrua ve Suksompong tarafindan Kuzey Nijerya'da bir eğitim hastanesinde sağlık çalışanları ile yapılan bir çalışmada katılımcıların tarafından radyasyon tehlikelerinin iyi bilinmesine rağmen radyasyondan korunmaya yönelik uygulamalarının yetersizliğine vurgu yapılmıştır. ${ }^{15}$ Paolicchi ve ark. tarafından İtalya'da radyoloji çalışanları ile yapılan diğer bir çalışmada ise katılımcıların \%90'ının radyasyondan korunma konularında yeterli bilgiye sahip olmalarına karşın, çoğunluğun radyolojik prosedürleri hafife aldıkları saptanmıştır. ${ }^{16} \mathrm{Bu}$ bakımdan çalışmamız sonuçları literatür ile uyumludur. Yine İtalya'da radyasyondan korunma uygulamalarının zayıf olduğu bir hastanede ortopedistler ile yapılan bir başka retrospektif 
çalışmada ise tıbbi radyasyona maruz kalan katılımcıların kalmayanlara oranla yaklaşık 7 kat daha fazla kansere yakalandıkları göz önüne alındığında, çalışmamızdaki katılımcıların koruyucu ekipman kullanmamalarına bağlı olarak kanser hastalığ1 yönünden risk altında olduklarını söylemek mümkündür. ${ }^{17}$ Radyoloji servislerinin çoğunda tiroid koruyucu, tamamına yakınında kurşun önlük bulunmasına rağmen, çalışanların ancak yarısı kurşun önlük kullanmaktadır. Güden ve ark. radyoloji çalışanları ile yaptığ 1 bir çalışmada bu oranın \%22,5 olduğu göz önüne alındığında, çalışmamızdaki katılımcıların koruyucu ekipman kullanımı konusunda farkındalıklarının daha yüksek olduğu söylenebilir. ${ }^{12}$ Bindman ve arkadaşlarının 1119 tomografi çekimini incelediği retrospektif çalışmada (2009) ise bir tomografi tetkikinin hastaları 2-31 msv arasında yüksek dozda radyasyona maruz bıraktığını belirtmelerinin yanında, bir koroner anjiografi uygulamasının kadınlarda $1 / 270$, erkeklerde ise $1 / 600$ oranında kanser oluşturabileceğini belirlemişlerdir. ${ }^{18}$ Yine Amerika'da yapılan başka bir retrospektif araştırmada tekrarlayan BT tetkikleri sonucu alınan kümülatif doz sonucuna bağlı kanser riskinin ciddi derecede artış gösterebileceği tespit edilmiştir. ${ }^{19}$ İngiltere'de radyolojik tetkiklerden dolayı her sene yaklaşık 100-150 kişinin kansere yakalandığ 1 tahmin edildiğinden yola çıkarak, her ne kadar hastalar kadar doğrudan radyasyona maruz kalmasalar da çalışanlarında koruyucu ekipman kullanmamaları, kanser riskini ciddi oranda arttırabileceğini düşünülmektedir. ${ }^{20}$

İyonize radyasyonun SSS'ni etkilediğini, IQ azalması ve mikrosefaliye neden olabileceğini bilen katılımcıların oranı \%59,8'dir. Çalışmamız sonuçlarına benzer şekilde Özel ve ark. klinisyen hekimlerin iyonize radyasyona yönelik bilgi düzeylerini araştırdıkları bir çalışmada katılımcıların büyük bölümünün iyonize radyasyonun duyarlılığının fazla olduğu fizyolojik alanlara yönelik yeterli bilgiye düzeyine sahip olduklarını ifade etmişlerdir. ${ }^{21}$ Denetimli alanlarda 18 yaş altında stajyer çalıştırılamayacağını bilenlerin sayısı ise, tüm katılımciların yalnızca \%36,1'ini oluşturmaktadır. Sorular arasında en az doğru cevabın bu soruya verildiği ve çalışanların yasal mevzuat hakkında yeterli bilgiye sahip olmadığı görülmüştür. Radyolojik tetkik ve tedaviler sırasında terapötik dokunmanın olamayacağını belirtenler yine toplam katılımcıların \%39,2'sini oluşturmaktadır.

Katılımcıların \%42,3'ünün az miktarda, $\% 18,6$ 'sının ise çok miktarda radyoaktif madde dökülmesi halinde nasıl temizleneceğini bilmediği görülmektedir. Anketi cevaplayanların \%81,4'ü kurşun ve beton bariyerlerin radyasyondan korunmada paravan oluşturduğuna doğru cevap verebilmiştir. \%53,6'l1k bir grup ise kurşun önlük ile batın bölgesini korumak suretiyle gebe çalışanların denetimli alanlarda bulunabileceğini belirtmişlerdir. Koçyiğit ve ark. hastane çalışanları ile yaptığı çalışmada ise katılımcıların yaklaşık \%34'ü gebelerin röntgen çekilirken ortamda bulunabileceğini belirtmişlerdir. ${ }^{22}$ Ramanathan ve Ryan tarafından radyoloji çalışanları ile yapılan diğer bir çalışmada hamilelik ve radyasyona maruz kalma konusunda çalışanların bilgi düzeyinin yetersiz olduğunu ifade etmişlerdir. ${ }^{23}$ Bizim çalışmamızdaki oranın yüksek olması soru kökeninde bulunan "kurşun önlüklü ile batın bölgesini korumak" şartından kaynaklandığı ve katılımcılar tarafından kullanılan bu önlügün gebelik döneminde radyasyondan korunmak için yeterli bir koşul olarak yorumladıkları düşünülmektedir.

Yaptıkları iş gereği radyasyona maruz kalma ihtimalleri olan çalışanların fiziksel dozimetre çeşitlerinden film, cep ya da termolüminesan dozimetrelerden birini kullanmalarının mevzuata göre yasal bir zorunluluk olduğu belirtilmektedir. ${ }^{24}$ Koruyucu önlük içine takılan dozimetrenin tüm vücudun aldığı radyasyon miktarını ölçtüğünü düşünen katılımcıların sayısı tüm katılımcı gurubun \%50,5'ini oluşturmaktadır. Görece olarak oldukça yüksek olduğu düşünülen bu oranın dozimetre kullanımında hatalara ve ön yargilara sebebiyet verebileceği düşünülmektedir. Maruz kalınan radyasyonun, radyasyon kaynağına bağlı olan 
doğrusal mesafeyle ters orantılı olarak azalacağ1 belirtilmektedir. $\mathrm{Bu}$ duruma bir örnek vermek gerekirse hastadan $60 \mathrm{~cm}$ uzakta duran kişi 1 doz radyasyon alırken, hastadan $30 \mathrm{~cm}$ mesafede duran bir başka kişi diğer bireye oranla yaklaşık 4 kat daha fazla radyasyona maruz kalmaktadir. ${ }^{25}$ Çalışmamızdaki katılımcıların \%27,8'inin radyasyon kaynağına olan uzaklığın, olumsuz etkiyi azaltan bir parametre olduğunu bilmediği görülmüștür. Ankete katılanların $\% 30,9$ 'u afet, yangin gibi acil durumlarda kurtarma ve ilkyardım çalışmalarının engellenemeyeceğini ve devam etmesi gerektiği sorusuna yanlış cevap vermiştir. Bu konuda bilgisi olmayan çalışanların, irtibatın kesilebileceği acil bir durum karşısında sergileyecekleri yanlış uygulamalarla kargaşaya ve dönüşü olmayan hatalara sebebiyet verebileceği düşünülmektedir.

\section{SONUÇ VE ÖNERILLER}

$\mathrm{Bu}$ çalışmada radyoloji çalışanlarının; radyasyon güvenliği hakkındaki bilgilerini, uygulamalarını ve bu konular hakkındaki görüşlerini saptamak amacıyla planlanmış ve çalışmanın sonucunda radyoloji çalışanlarında radyasyon güvenliği ile ilgili birçok konuda bilgi eksiği olduğu, bazı konularda eksik veya mevzuata uygun olmayan bilgiye sahip oldukları saptanmıştır. $\mathrm{Bu}$ nedenle, hasta ve çalışan güvenliğinin sağlanmasına yönelik başta radyoloji alanında çalışan personel olmak üzere, tüm hastane çalışanlarına yönelik konu ile ilgili hizmet içi eğitimlerin periyodik aralıklarla planlanması ve mesleki eğitimlere radyasyon güvenliği ile ilgili derslerin eklenmesinin, konu hakkındaki farkındalığı arttıracağı düşünülmektedir.

KAYNAKLAR

1. Aydıngöz, İ.E. (1996). İyonize Radyasyonun Deri ve Yara İyileşmesi Üzerine Etkileri. In: C. Erdem, C.R. Celebi (Ed.) Tüm Yönleriyle Yara İyileșmesi (47-56). Ankara: Ayrıntı Matbaacılık Ltd.

2. Eijkelhof, H. and Millar, R. (1988). "Reading about Chernobyl: The Public Understanding of Radiation and Radioactivity". School Science Review, 70 (251), 35-41.

3. Oyar, O. (1998). Radyolojide Temel Fizik Kavramlar, İstanbul: Nobel Tip Kitabevleri.

4. Köklü, N. (2006). Radyasyonun İnsan Sağlığı Üzerindeki Etkileri ve Tipta Uygulama Alanları. (Yüksek Lisan Tezi9. Selçuk Üniversitesi Fen Bilimleri Enstitüsü, Konya.

5. Türkiye Atom Enerjisi Kurumu. (2019). "Radyasyonla Birlikte Yasıyoruz: Doğal Radyasyon Kaynakları". Erişim adresi: http://www.taek.gov.tr. (Erişim tarihi: 15.04.2019)

6. Coşkun, Ö. (2011). "İyonize Radyasyonun Biyolojik Etkileri’. Teknik Bilimler Dergisi, 1 (2), 13-17.

7. Türkiye Atom Enerjisi Kurumu. (2010). "Radyasyon, İnsan ve Cevre El Kitabı", http://kurumsalarsiv.taek.gov.tr/handle/1/22. (ET:18.04.2019).
8. Saygın, M, Yaşar, S, Çetinkaya, M, Kayan, M, Özgüner, M.F. ve Korucu, C.Ç. (2011). "Radyoloji Çalışanlarında Depresyon ve Anksiyete Düzeyleri”. S.D.Ü. Sağlık Bilimleri Enstitüsü Dergisi, 2 (3), 139-144.

9. Solmaz Alkaya, F. ve Özatamer, O. (2012). "Radyasyon ve Radyoaktif Madde Toksisitesi”. Turkiye Klinikleri J Anest Reanim, 10 (1), 28-34.

10. Mendelsohn, D, Strelzow, J, Dea, N, Ford, N. L, Batke, J, Pennington, A, Yang, K, Ailon, T, Boyd, M, Dvorak, M, Kwon, B, Paquette, S, Fisher, C. and Street, J. (2016). Patient And Surgeon Radiation Exposure during Spinal İnstrumentation Using İntraoperative Computed Tomography-Based Navigation. The Spine Journal: Official Journal of The North American Spine Society, 16 (3), 343-354.

11. Riis, J, Lehman, R.R, Perera, R.A, Quinn, J.R, Rinehart, P, Tuten, H.R. and Kuester, V. (2017). A Retrospective Comparison Of İntraoperative CT And Fluoroscopy Evaluating Radiation Exposure In Posterior Spinal Fusions for Scoliosis. Patient Safety in Surgery, 11, 32.

12. Güden, E, Öksüzkaya, A, Balcı, E, Tuna, R, Borlu, A. ve Çetinkara, K. (2012). "Radyoloji Çalışanlarının Radyasyon Güvenliğine İlişkin Bilgi, Tutum ve Davranıșı". Sağlıkta Performans ve Kalite Dergisi, 3 (1), 29-45.

13. Çimen, B, Erdoğan, M. ve Oğul, R. (2017). "İyonlaştırıc Radyasyon ve Korunma Yöntemleri”. S.Ü. Fen Fakültesi Fen Dergisi, 43 (2), 139-147. 
14. Awosan, K.J, Ibrahim, M, Saidu, S.A, Ma'aji, S.M Danfulani, M, Yunusa, E.U, Ikhuenbor, D.B. and Ige, T.A. (2016). "Knowledge of Radiation Hazards, Radiation Protection Practices and Clinical Profile of Health Workers in a Teaching Hospital in Northern Nigeria". Journal of Clinical and Diagnostic Research JCDR, 10 (8), 6.

15. Khamtuikrua, C. and Suksompong, S. (2020). "Awareness About Radiation Hazards and Knowledge About Radiation Protection Among Healthcare Personnel: A Quaternary Care Academic Center-Based Study". SAGE Open Medicine, 8, 4 .

16. Paolicchi, F, Miniati, F, Bastiani, L, Faggioni, L, Ciaramella, A, Creonti, I, Sottocornola, C, Dionisi, C. and Caramella, D. (2016). "Assessment of Radiation Protection Awareness And Knowledge about Radiological Examination Doses among Italian Radiographers”. Insights Into Imaging, 7 (2), 233-242.

17. Bratschitsch, G, Leitner, L, Stücklschweiger, G.P, Sadoghi, P, Puchwein, A.L. and Radl, R. (2019). "Radiation Exposure of Patient and Operating Room Personnel by Fluoroscopy and Navigation during Spinal Surgery". Sci Rep, 9, 17652

18. Bindman, R.S, Lipson, J, Marcus, R, Pyo Kim, K, Mahesh, M, Gould, R, González, A.B. and Miglioretti, D.L. (2009). "Radiation Dose Associated With Common Computed Tomography Examinations and the Associated Lifetime Attributable Risk of Cancer". Arch Intern Med, 169 (22), 2078-2086.

19. Sodickson, A, Baeyens, P.F, Andriole K.P, Prevedello L.M, Nawfel R.D. and Hanson, R.K. (2009). "Recurrent CT, Cumulative Radiation Exposure, and Associated Radiationinduced Cancer Risks From CT of Adults". Radiological Society of North America, 251 (1), 175184.

20. Shiralkar, R.S. (2003). "Doctors' Knowledge of Radiation Exposure: Questionnaire Study". BMJ, 327 (3), 371-372.

21. Özel, D, Özel, B.D, Özkan, F, Akan, D, Özer, Ö. ve Halefoğlu, A.M. (2015). "Physicians' Knowledge About İonising Radiation And Radiological İmaging Techniques: A Cross Sectional Survey". Acta Radiologica, 52(5), 537-539.

22. Koçyiğit, A.S, Kaya, F.A, Çetin, T, Kurban, I, Erbas, T, Ergin, A.D, Ağladıoğlu, K, Herek, D. ve Karabulut, N. (2014). "Radyolojik Tetkikler Sirasında Maruz Kalınan Radyasyon Hakkında Sağlık Personelinin Bilgi Düzeyleri”. Pamukkale Tıp Dergisi, 7 (2), 137-142.

23. Ramanathan, S. and Ryan, J. (2015). "Radiation Awareness Among Radiology Residents,Technologists, Fellows And Staff: Where Do We Stand?", Insights Imaging, 6, 133-139.

24. Karataşlı, M. ve Özer, T. (2018). "İş Güvenliğinde Dozimetreler”. İstanbul Aydın Üniversitesi Dergisi, 10 (1), 15-31.

25. Mudun, A. (2009). "Meme Kanserinde İntraoperatif Gama Prob Kullanımında Radyasyon Güvenliği”. The Journal of Breast Health, 5 (3), 115-118. 